\title{
Impact of Biological Agents and Tissue Engineering Approaches on the Treatment of Rheumatic Diseases
}

\author{
Marta Alves da Silva, M.Sc., ${ }^{1,2, *}$ Albino Martins, B.Sc., ${ }^{1,2, *}$ Ana A. Teixeira, M.D. ${ }^{3}$ \\ Rui L. Reis, C.Eng., M.Sc., Ph.D., D.Sc., ${ }^{1,2}$ and Nuno M. Neves, M.Sc., Ph.D.,
}

The treatment of rheumatic diseases has been the focus of many clinical studies aiming to achieve the best combination of drugs for symptom reduction. Although improved understanding of the pathophysiology of rheumatic diseases has led to the identification of effective therapeutic strategies, its cure remains unknown. Biological agents are a breakthrough in the treatment of these diseases. They proved to be more effective than the other conventional therapies in refractory inflammatory rheumatic diseases. Among them, tumor necrosis factor inhibitors are widely used, namely Etanercept, Infliximab, or Adalimumab, alone or in combination with disease-modifying antirheumatic drugs. Nevertheless, severe adverse effects have been detected in patients with history of recurrent infections, including cardiac failure or malignancy. Currently, most of the available therapies for rheumatic diseases do not have sufficient tissue specificity. Consequently, high drug doses must be administrated systemically, leading to adverse side effects associated with its possible toxicity. Drug delivery systems, by its targeted nature, are excellent solutions to overcome this problem. In this review, we will describe the state-of-the-art in clinical studies on the treatment of rheumatic diseases, emphasizing the use of biological agents and target drug delivery systems. Some alternative novel strategies of regenerative medicine and its implications for rheumatic diseases will also be discussed.

\section{Rheumatic Diseases and Categories of Treatments}

$\mathbf{T}$ HERE ARE OVER 100 TYPES of rheumatic diseases, arthritis, and related conditions. Examples of inflammatory rheumatic diseases include rheumatoid arthritis (RA), ankylosing spondylitis (AS), psoriatic arthritis (PsA), systemic lupus erythematosus, juvenile idiopathic arthritis (JIA), and osteoarthritis (OA). ${ }^{1,2}$ These diseases affect people of all ages and genders, and until today, its causes remain unknown, as well as its cure. According to the Center for Disease Control and Prevention, over 46 million people in the United States have some form of arthritis or chronic joint symptom.

There are several treatments aiming at easing pain, inflammation, and joint damage progression. The plans of treatment often include short-term and long-term relieve approaches. Short-term treatments involve pain relievers such as nonsteroidal anti-inflammatory drugs, joint immobilization periods, massage, and heat or cold applications.
Long-term management includes medication, weight reduction plans, exercise, or surgery. Conventional drug treatment for rheumatic inflammatory diseases combines basically a symptom-modifying antirheumatic drug with diseasemodifying antirheumatic drugs (DMARDs). The combination of symptom-modifying antirheumatic drugs with DMARDs can slow inflammation and, in some cases, modify the progression of the disease. ${ }^{3}$ In this review, we will focus on longterm medication with DMARDs and biological agents. Additionally, we will discuss novel possibilities based on cell therapy and tissue engineering for the treatment of rheumatic diseases.

\section{Biological Agents in the Treatment of Rheumatic Diseases}

Advances in biotechnology have led to the development of agents that therapeutically target specific components of

\footnotetext{
${ }^{1} 3 \mathrm{~B}$ 's Research Group-Biomaterials, Biodegradables, and Biomimetics, Department of Polymer Engineering, University of Minho, Guimarăes, Portugal.

${ }^{2}$ PT Associated Laboratory, Institute for Biotechnology and Bioengineering, Braga, Portugal.

${ }^{3}$ Portuguese Institute of Rheumatology, Lisbon, Portugal.

*These two authors contributed equally to this work.
} 
the deregulated immune system, known as "biological agents." ${ }^{4,5}$ Among them, tumor necrosis factor $\alpha$ (TNF $\left.\alpha\right)$ and interleukin- $1 \alpha$ and $\beta$ have a significant role in the pathogenesis of rheumatic diseases. ${ }^{6,7}$ Biological agents are partially or fully humanized recombinant proteins that target different pathways of the immune response. Further information on the safety and efficacy of TNF blockers can be obtained, for example, in Ref. ${ }^{8}$ The most used biological agents for the treatment of rheumatic diseases and their characteristics and secondary effects are also presented in Table 1.

Among the different biological agents used in clinical practice, TNF $\alpha$ inhibitors have proven to be highly effective in the treatment of advanced rheumatic diseases, such as RA, AS, PsA, or JIA, ${ }^{1,4,6,9,10}$ reducing their symptoms, improving the physical function of joints, and inhibiting joint damage progression. ${ }^{7}$ The cost of TNF $\alpha$ inhibitors is one of the main limitations associated with this therapy: they are considerably more expensive than the traditional DMARDs. Considering the high cost of these drugs, several strategies of combination of these agents with DMARDs are being increasingly studied, ${ }^{5,8,11}$ as is explained in the next section.

\section{Long-Term Efficacy of Biological Agents and Their Impact on the Patients' Quality of Life}

Various studies showed the efficacy of biological agents and most of the patients respond well to the treatments using these medications alone or in combination with others DMARDs. According to the guidelines of the British Society of Rheumatology, the treatment of active AS with TNF blockers leads to a sustained response for over 2 years, most patients showing tolerance to these drugs. ${ }^{12}$ Another study showed a rapid clinical improvement of patients with AS (as early as 2 weeks) after the onset of anti-TNF therapy. ${ }^{13}$ Chronic therapy with Adalimumab improved measures of fatigue and health-related quality of life in patients with longstanding RA diagnosis. This effect was maintained for a mean of 1.6 years in all applied measures. ${ }^{14}$ Subcutaneous administration of Etanercept was effective and generally well tolerated in large-scale clinical trials in patients with RA. ${ }^{15}$ A therapy combining methotrexate (MTX) with Infliximab, Etanercept, or Adalimumab in RA was generally superior to monotherapy in reducing the disease activity and joint damage, as well as improving health-related quality of life. ${ }^{15,16}$

Before initiating the therapy with TNF inhibitors, some contraindications must be considered by physicians to minimize the risks including active infections, history of recurrent or chronic infections, cardiac failure, or malignancy. 8,17 The blockade of a critical proinflammatory cytokine in patients already taking other anti-inflammatory agents may trigger severe infections. The most severe secondary effect of anti-TNF $\alpha$ was tuberculosis. ${ }^{8,18-20}$ The development of antibodies against the TNF $\alpha$ inhibitors is another possible problem, ${ }^{5,17,18}$ as well as lupus-like syndrome. ${ }^{9}$ When the first TNF antagonist fails, perhaps the best alternative is to switch to a different type of biological agent such as Abatacept or Rituximab and, in the case of adverse event to a previous treatment, to another TNF inhibitor. ${ }^{21}$

To reach effective drug concentrations in the affected joint tissues, high doses of the therapeutic agent must be administered systemically, which may lead to significant adverse systemic and extra-articular side effects. Currently, most of the available therapies for rheumatic diseases do not have tissue specificity and have a ubiquitous distribution of molecular targets. Reduction in drug doses may attenuate toxicity, being a plausible solution, but may lead to reduced therapeutic efficacy. To overcome these limitations, targeted drug delivery systems may provide excellent solutions by incorporating the available antirheumatic drugs and releasing them at the target sites. ${ }^{22}$

\section{Novel Approaches for Targeted Delivery of Antirheumatic Drugs}

Drug delivery systems have been developed in several emerging research fields such as tissue engineering and regenerative medicine, as a method to address the problems associated with conventional drugs and improve their phar-

Table 1. Biological Agents Used in Clinical Practice for the Management of Rheumatic Diseases

\begin{tabular}{|c|c|c|c|c|}
\hline Trade name & Type & $\begin{array}{l}\text { Mechanism } \\
\text { of action }\end{array}$ & Application & Secondary effects \\
\hline Abatacept & CTLA4 Ig & $\begin{array}{l}\text { Costimulation } \\
\text { inhibitor }\end{array}$ & RA; CV; SLE & Serious infection \\
\hline Adalimumab & Anti-TNF $\alpha$ & TNF inhibitor & RA; AS; PsA & $\begin{array}{l}\text { Infections, fatal sepsis, } \\
\text { demyelinating events }\end{array}$ \\
\hline Anakinra & IL-1ra & IL1 inhibitor & RA; AS & Severe infection \\
\hline Etanercept & $\begin{array}{l}\mathrm{TNF}-\alpha \mathrm{R} / \mathrm{Fc}_{\mathrm{C}} \\
\text { fusion protein }\end{array}$ & TNF inhibitor & RA; AS; SA; PsA; JIA & Infections, bronchitis \\
\hline Infliximab & Anti-TNF $\alpha$ & TNF inhibitor & RA; AS; SA; PsA; DM/PM & $\begin{array}{l}\text { Tuberculosis, lupus-like } \\
\text { syndrome, heart failure, } \\
\text { pancreatitis, liver failure }\end{array}$ \\
\hline Rituximab & Anti-CD20 mAb & B-cell depletion & RA; CV; SLE & $\begin{array}{l}\text { Cardiac arrest, infections, } \\
\text { immune toxicity }\end{array}$ \\
\hline
\end{tabular}

Table adapted from Konttinen $e t$ al. ${ }^{3}$ and Diaz-Borjon et $a .^{8}$

RA, rheumatoid arthritis; CV, cryoglobulinemic vasculitis; SLE, systemic lupus erythematosus; AS, ankylosing spondylitis; PsA, psoriatic arthritis; IL, interleukin; SA, secondary amyloidosis; JIA, juvenile idiopathic arthritis; DM, dermatomyositis; PM, polymyositis. 
macological properties. The means by which a drug is released may have a considerable effect on its efficacy and therapeutics. Drug delivery systems have been designed using different polymers of either synthetic or natural origin. There is a great potential to further develop these systems, because they allow the manipulation of the kinetics of release, by playing with specific parameters such as polymer type, molecular weight, or processing method. ${ }^{23,24}$ In the development of synthetic polymers for drug delivery, both the polymer and the bioactive agent are generally mixed and processed into a suitable carrier. As the bioactive agent is deeply inside the polymer, its release will also depend on the kinetics of biodegradation of the polymer. ${ }^{25,26}$ The previous systems depend mostly on diffusion and degradation rates, whereas several new systems depend more on the status of the regenerative area to release bioactive agents. For example, hydrogels have been developed to respond to environmental changes, such as compressive stimulation of the matrix, providing mechanically controlled release of bioactive agents or specific growth factors. ${ }^{25}$

To achieve a better control over drug release, several technologies have been developed. Most of these procedures are based on a combination of bioactive agents and biomaterials by bonding. Many examples of these strategies have been reported in recent literature. ${ }^{27}$ Materials used in these processes include poly(D,L-lactide-co-glycolide) (PLGA), ${ }^{28}$ polycaprolactone, ${ }^{29}$ chitosan, ${ }^{30}$ or starch. ${ }^{31}$

Intra-articular injection (IA) of drug delivery systems enables the incorporated drug to be released in the proximity of the targeted area. IA of drugs presents the advantage of reducing the amount of drug required at the injured site and minimizing the exposure to the drugs to unintended sites. ${ }^{32}$ Nevertheless, one of the main challenges for IA formulation development is to achieve a long-lasting release of the drug. ${ }^{33}$ Most of the new chemical drugs used for therapeutic purposes are not soluble in water, which is a major adverse factor conditioning its effectiveness. ${ }^{34}$ Therefore, novel strategies of drug delivery in situ are being investigated and developed, such as micro- or nanoparticles and liposomes.

Microparticulate systems showed to be very promising for controlled release applications, ${ }^{23,33}$ namely as carriers of differentiation agents such as dexamethanone. ${ }^{29}$ Indomethacinbiodegradable and biocompatible polymer conjugates were developed to target the intra-articular region. Namely, PLGA microspheres incorporating a polyethylene glycol derivative $\left(\right.$ Labrafil ${ }^{\circledR}$ ) was used to prolong indomethacin release in the joint for up to 19 days. ${ }^{28} \mathrm{~A}$ different drug carrier comprises paclitaxel-loaded microspheres of poly(L-lactic acid) showing a sustained release over 30 days and an efficient intra-articular reduction of inflammation conditions (i.e., joint swelling, cell infiltration, proteoglycan loss, chondrocyte necrosis) in rabbit models of antigen-induced arthritis. ${ }^{35}$ Besides these drug carriers, there has been relatively few experiments on the development of other carriers to deliver antirheumatic drugs, namely DMARDs, such as albumin-MTX conjugate tested in an arthritic rodent mode ${ }^{36}$ or MTX-loaded PLLA microspheres injected intra-articularly in healthy rabbits. ${ }^{37}$ Despite the limitations of systemic administration of antirheumatic drugs, IA of DMARDs has not been an area of much interest or investigation because these drugs were not expected to remain in the joints. ${ }^{38}$
Polymeric nanoparticles were proposed for controlled release of different bioactive agents. ${ }^{28,29,39-41}$ These carriers were extensively studied for targeting articular cartilage diseases such as OA. Nanoparticles for this type of application generally contain a specific cartilage-binding moiety. ${ }^{23}$ Moreover, to reach competent carrier penetration into the cartilage, the carrier size may play an essential role. This aspect was demonstrated by Rothenfluh et al. ${ }^{42}$ for nanoparticles coated with collagen II-binding peptide. In a recent study, folic acid was coupled to the surface amino groups of poly(amidoamine) dendrimers and loaded with indomethacin (a nonsteroidal anti-inflammatory drug used for the management of RA, OA, and acute gout). ${ }^{43}$ Results demonstrated that folate-dendrimer conjugates are a suitable vehicle for site-specific delivery of an antiarthritic drug to active inflammation sites, namely the inflamed paw of arthritic rats. Our group has been studying targeted drug delivery systems for cartilage and bone. In a recent study, poly(amidoamine) dendrimers conjugated with carboxymethylchitosan nanoparticles proved to be very interesting for mesenchymal stem cell (MSC) studies and application in regenerative medicine. In this study, the materials were able to induce osteogenic differentiation of rat MSCs in vitro. ${ }^{40}$

Liposomes are another type of carrier used for drug delivery applications. Research on this carrier has mainly been focused on increasing its retention as a function of particle size and biocompability. ${ }^{23,33}$

Although some forms of arthritis may be treated by the intra-articular administration of drugs such as glucocorticoids, this approach may be limited by the rapid clearance of the drugs from the synovial space, resulting in only transient efficacy. The use of polyethylene glycol liposomes ${ }^{44}$ and PLGA nanospheres ${ }^{45}$ as drug carriers for the localized delivery of glucocorticoids into the synovial space has been proposed. Polymeric carriers were preferred, because a proper design of linkage between the drug and the polymer backbone allows a finely controlled kinetics of local drug release. Conversely, accumulation of the liposomes in liver and spleen is well documented. Recently, Wang et al. ${ }^{46}$ developed a novel $\mathrm{pH}$-sensitive drug delivery system of dexamethasone based on an $\mathrm{N}$-(2-hydroxypropyl)methacrylamide copolymer and showed that the delivery system specifically accumulates in inflamed joints of an adjuvant-induced arthritis rat model.

Local application of anti-inflammatory and osteo- and chondroprotective agents by means of cellular gene therapy is an attractive alternative for cartilage repair, because it may provide long-term expression of the therapeutic agents and minimize systemic adverse effects. ${ }^{47,48}$ This treatment strategy is based on the use of genetically engineered cells that have the ability to migrate into the sites of active autoimmune inflammation to express and deliver therapeutic gene products. There are many strategies used for the delivery of exogenous cDNAs for the treatment of cartilage diseases. All these require an efficiently delivery of the cDNA of interest to the target cells to enable a sustained and long-lasting transgene expression to trigger the desired biological response. ${ }^{49}$ There are two ways for IA gene delivery: direct or indirect. The direct way consists of an in vivo approach, applying the vector directly in the joint. ${ }^{49}$ The indirect method is based ex vivo and entails genetically modified cells, which 
are further transplanted into the body. In vivo approaches have the advantage of being less invasive than the ex vivo ones. ${ }^{50}$ They are also more economic because they do not require cell manipulation. Nevertheless, the transfected cells are injected directly into the body, increasing the risks for the patients. ${ }^{49,51}$ Ex vivo approaches are more invasive and expensive, but they allow for a better control of the transduced cells and also their testing for safety before the transplant. ${ }^{49,51}$ More details about the specific aspects of these technologies can be obtained from Refs. ${ }^{43-45}$

The administration of targeted signaling molecules and growth factors is another adequate way to manipulate cell behavior. The use of proper growth factors to direct stem cells into the chondrogenic lineage can lead to the formation of a cartilage-like tissue by transplanted cells. ${ }^{52-56}$ Cell-mediated gene transfer allows the transplantation within the tissue of therapeutically relevant cell populations previously directed into specific cell lineages with differentiation factors.

There are three types of primary candidate cell types used to target genetic modifications for the treatment of damaged articular cartilage: synovial cells, ${ }^{55-57}$ chondrocytes, ${ }^{52,53,58}$ and MSCs. ${ }^{54,59-61}$ There are several genes involved in cartilage development and maintenance. These genes have been broadly studied as target genes for modification of cells involved in the repair of articular cartilage. Transduction of chondrocytes has been performed of several genes involved in its signaling pathways and extracellular matrix, such as the transcription factor sry (sex-determining region $\mathrm{Y}$ )-Box9 (Sox9), ${ }^{62,63}$ bone morphogenic protein-2 (BMP-2), $52,53,55$ transforming growth factor (TGF)- $31{ }^{64}$ BMP-2, ${ }^{53,64}$ and insuline-like growth factor (IGF-1). ${ }^{64}$ MSCs have also been transduced with several genes to enhance their chondrogenic differentiation, such as BMP- $4,{ }^{65,66}$ TGF- $\beta 1,{ }^{67}$ or TGF- $\beta 3{ }^{68}$

For ex vivo gene transfer approaches, different vectors have been developed, namely viral and nonviral. Adenoviral vectors have been considered to be most efficient and capable of infecting a wide variety of cell types. ${ }^{50}$ Nonviral gene transfer is considered to be less efficient than the viral vectors, but allow large-scale preparations, with low costs, and there is no risk of generating replication-competent pathogenic viruses. Nonviral vectors are also mainly nonimmunogenic. ${ }^{69}$

A gene delivery for many applications in vivo can be achieved by complexing plasmid DNA with chemical agents such as polymers ${ }^{70}$ and liposomes. ${ }^{69}$ Another approach for controlled gene delivery for tissue engineering purposes is loading biodegradable materials with DNA molecules. ${ }^{71-73}$ Collagen-based scaffolds have been investigated as carriers for plasmid DNA. ${ }^{71,73}$ For example, Capito and Spector have demonstrated that collagen-based scaffolds can serve as nonviral gene delivery vehicles for IGF-1, providing a locally sustained therapeutic level of IGF-1, which enhanced cartilage formation. ${ }^{71}$

Several gene therapy approaches have been established in preclinical animal models, namely a murine model of collagen-induced arthritis and an immunodeficient mouse model of RA. ${ }^{47,48}$ The latest model enables exploring new gene therapy approaches from pure animal model research being one step closer to the human RA patients by using human "vehicle cells." At the moment, some human clinical phase I trials of arthritis gene therapy are being performed. ${ }^{74}$

\section{Alternative Strategies for Regenerative Medicine of Rheumatic Diseases}

Over the last few years, immunotherapy targeting antiinflammatory cytokines aims at delaying the progress of the degeneration of the joint cartilage and bone loss, but not its regeneration. To address the need for improved therapies to promote cartilage and bone repair or regeneration, a number of novel tissue engineering approaches have been developed for the treatment of rheumatic diseases. ${ }^{75}$ Several synthetic and natural materials were already proposed for controlled release in the context of tissue regeneration, ${ }^{76-79}$ as described in the previous section. Starch-based materials and composites are among those biomaterials and have shown to induce lower inflammatory cytokines, compared with poly(L-lactide) ${ }^{76}$ Several studies show the efficiency and the utility of starch in different systems for drug delivery, such as fibers, ${ }^{80}$ microspheres, ${ }^{81}$ or nanoparticles. ${ }^{82}$ Starch-based microparticles were developed in our group for drug delivery systems ${ }^{83}$ and showed to be viable as carriers for the incorporation and release of corticosteroids ${ }^{77}$ and growth factors $^{29,31,84}$ and as supports for cells. ${ }^{79}$

Autologous chondrocyte transplantation (ACT) in human cartilage defects has shown promising results in early clinical studies, but little difference in the efficacy was observed in comparison to surgical procedures such as mosaicoplasty. ${ }^{85}$ Further, ACT has been associated with significant donor-site morbidity and the initiation of osteoarthritic changes in the joint due simply to harvest of the donor cartilage, indicating the need for alternative cell sources for the tissue-engineered repair of cartilage. ${ }^{86}$ Matrix-assisted autologous chondrocyte implantation, on the other hand, uses biomaterials to sustain the transplant. Different resorbable transplants were tested in the clinic and presents promising results. ${ }^{87}$ For cartilage repair, chondrocyte-seeded 3D biomaterials already reached the clinic. ${ }^{88}$ The biomaterial ensures initial mechanical stability and an appropriated 3D environment for cell proliferation and differentiation. Thus, biomaterials avoid the need to use chondral sutures, one of the major drawbacks of the ACT, and because of the possibility of stable transplant fixation, a healthy cartilage surrounding is not required. $^{75}$

MSCs are of special interest as they could be isolated from many adult tissue types and are characterized by their ability to undergo extensive self-renewal in vitro and to assume multilineage differentiation. ${ }^{89}$ Unlike chondrocytes, these cells are available in a unlimited fashion and do not lose their phenotype during expansion. ${ }^{90}$ Moreover, MSCs are less immunogenic than chondrocytes, avoiding allogenic rejection, and have been tested successfully in animal models of arthritis. ${ }^{91}$ Importantly, they secrete or can be genetically manipulated to secrete immunosuppressive factors and therapeutic agents that target inflammatory tissues. The challenge in using MSCs as a cell source for articular cartilage tissue engineering is therefore to maintain the MSC-derived chondrocytes in the prehypertrophic state and prevent them from undergoing terminal differentiation as seen in the growth plate. ${ }^{92}$ MSCs have been used in OA therapy by means of delivery to the site defect, either by direct IA or using a scaffold or matrix to support the cells. ${ }^{90}$ Recently, it was demonstrated the potential of gelatin microspheres containing TGF- $\beta 3$ to induce chondrogenic differentiation of 
MSCs isolated from bone marrow of New Zealand rabbits. ${ }^{93}$ Nevertheless, a study that investigated the chondrogenesis of bone marrow-derived MSCs in aggregate cultures following genetic modification with adenoviral vectors encoding TGF- $\beta 1$ and BMP-2 demonstrated that transgene expression was highly transient, showing a marked decrease after 7 days. ${ }^{60}$ More recently, Sun et al. showed that adenoassociated virus effectively transduced human bone marrowderived MSCs. ${ }^{73}$

Some nanofibrous polymeric membranes were successfully developed in our laboratory using the electrospinning technology. They were used for production of cartilage tissueengineered tissue. It was generated effectively and showed to have the potential for the treatment of cartilage degenerative diseases. These membranes are currently under patent process (WO 2006/138552 A2). In a recent study using bovine articular chondrocytes, starch-polycaprolactone (SPCL) and polycaprolactone nanofiber meshes were shown to be suitable as a support for cartilaginous extracellular matrix production. ${ }^{94}$

Hydrogels have also been described as good matrices to support cells, particularly chondrocytes, as stated previously. A gene-activated chitosan-gelatin matrix was developed by Guo et al. in 2006, ${ }^{70}$ for cartilage defect restoration. The referred matrixes were capable of releasing TGF- $\beta 1$ in a controlled fashion and promoted chondrocyte proliferation. Chitosan-based scaffolds were also successfully used in a cartilage defect model in sheep. ${ }^{95}$ A biodegradable hydrogel composite of oligo(poly(ethylene glycol) fumarate) with encapsulated rabbit marrow MSCs and gelatin microparticles loaded with TGF- $\beta 1$ was tested for cartilage tissue engineering. It was demonstrated that the encapsulated rabbit MSCs differentiated into chondrocyte-like cells, suggesting the potential of this strategy for localized delivery of stem cells and bioactive molecules. ${ }^{96}$ Another study using rabbit MSCs evaluated the efficacy of IA of chondroitin sulphate carried by a hydrogel in the treatment of chondral defects in adult rabbit models. The histological and biomechanical properties of the repaired cartilage were improved, which suggests that this may be an effective treatment for cartilage injury. ${ }^{97}$ Recently, the potential of a composite hydrogel was tested with bovine articular chondrocytes. Cells were encapsulated in the hydrogel and the results showed that they survived and retained their chondrocytic morphology. 98

We have been developing several natural-based hydrogels using, for example, starch, ${ }^{99}$ gellan gum, ${ }^{100}$ or chitosan, ${ }^{101}$ the last two being specific for cartilage regeneration. More recently, a novel injectable carrageenan/fibrin/hyaluronic acid-based hydrogel with in situ gelling properties was used for cartilage tissue engineering purposes. ${ }^{102}$ When seeded with human articular chondrocytes, this injectable hydrogel was able to regenerate and repair a lesion in bovine articular cartilage, showing great potential as a novel delivery system for cartilage tissue engineering. ${ }^{102}$

However, an open question of cell-based therapies is the unknown influence of the inflammatory conditions observed in the joint of patients with OA or inflammatory arthritis on cell suspensions or 3D constructs. To overcome this inflammatory condition, the systemic or local anti-inflammatory drugs and biological agents can be applied combined or separately, released in a controlled manner from the implant itself, or secreted by genetically manipulated MSCs.
The future generation of regenerative medicine for rheumatic diseases is focused on in situ therapies. This strategy consists in cell-free chondroinductive scaffold implantation combined with chemotactic molecules that allow the recruitment of joint-inherent and surrounding cells to traumatic or arthritic diseased joints, and their subsequent contribution for growth and differentiation in factor-guided joint repair. ${ }^{103}$ It is believed that the biological agents and anti-inflammatory drugs will complement the in situ therapy of chronic joint diseases, enhancing joint tissue regeneration and preventing the degradation of the native and neotissues formed. $^{75}$

\section{Conclusions}

The treatment of rheumatic diseases has been focused on the achievement of the best drug combination for symptom reduction. Although improved understanding of the pathophysiology of rheumatic diseases has led to the identification of effective therapeutic strategies, its cure remains unknown. Even so, biological agents proved to be more effective than other conventional therapies in refractory inflammatory rheumatic diseases. Among them, TNF inhibitors are widely used, namely Etanercept, Infliximab, or Adalimumab, alone or in combination with DMARDs.

Local drug delivery systems are promising solutions regarding tissue specificity. They allow a targeted delivery of the drug at the damage tissue, reducing side effects associated with its possible toxicity. Alternative strategies for regenerative medicine are based on a number of novel tissue engineering approaches, which have been developed for the treatment of rheumatic diseases. Recently, natural-based polymeric scaffolds have showed promising results for bone or cartilage regeneration. These scaffolds could be improved in a drug delivery system to perform an "on-site" treatment. Further optimization will be needed, but this is a step forward in joining the two concepts of therapies in one major strategy for rheumatic disease treatment.

\section{Acknowledgments}

The authors state that there is no conflict of interests, including financial, relationships, or affiliations relevant for the subject. M. Alves da Silva and A. Martins acknowledge the Portuguese Foundation for Science and Technology for their Ph.D. grants and European NoE EXPERTISSUES (NMP3-CT2004-500283).

\section{Disclosure Statement}

No competing financial interests exist.

\section{References}

1. Klareskog, L., van der Heijde, D., de Jager, J.P., Gough, A., Kalden, J., Malaise, M., Mola, M.E., Pavelka, K., Sany, J., Settas, L., Waydula, J., Pedersen, R., Fatenejad, S., and Sanda, M. Therapeutic effect of the combination of etanercept and methotrexate compared with each treatment alone in patients with rheumatoid arthritis: double-blind randomised controlled trial. Lancet 363, 675, 2004.

2. Rat, A.C., and Boissier, M.C. Rheumatoid arthritis: direct and indirect costs. Joint Bone Spine 71, 518, 2004. 
3. Konttinen, Y.T., Seitsalo, S., Lehto, M., and Santavirta S. Current management: management of rheumatic diseases in the era of biological anti-rheumatic drugs. Acta Orthop 76, 614, 2005.

4. Kavanaugh, A. Economic consequences of established rheumatoid arthritis and its treatment. Best Pract Res Clin Rheumatol 21, 929, 2007.

5. Yen, J.H. Treatment of early rheumatoid arthritis in developing countries. Biologics or disease-modifying antirheumatic drugs? Biomed Pharmacother 60, 688, 2006.

6. Finckh, A., and Gabay, C. At the horizon of innovative therapy in rheumatology: new biologic agents. Curr Opin Rheumatol 20, 269, 2008.

7. Stubgen, J.P. Tumor necrosis factor-alpha antagonists and neuropathy. Muscle Nerve 37, 281, 2008.

8. Diaz-Borjon, A., Weyand, C.M., and Goronzy, J.J. Treatment of chronic inflammatory diseases with biologic agents: opportunities and risks for the elderly. Exp Gerontol 41, 1250, 2006.

9. Mor, A., Pillinger, M.H., Wortmann, R.L., and Mitnick, H.J. Drug-induced arthritic and connective tissue disorders. Semin Arthritis Rheum 38, 249, 2008.

10. Ravindran, V., Scott, D.L., and Choy, E.H. A systematic review and meta-analysis of efficacy and toxicity of disease modifying anti-rheumatic drugs and biological agents for psoriatic arthritis. Ann Rheum Dis 67, 855, 2008.

11. Meyer, O., de Bandt, M., Berthelot, J.M., Cantagrel, A., Combe, B., Fautrel, B., Flipo, R.M., Liote, F., Maillefert, J.F., Sabaux, A., Wendling, D., Guillemin, F., and Le Loet, X. Clinical practice format for choosing a second-line disease modifying anti-rheumatic drug in early rheumatoid arthritis after failure of 6 months' first-line DMARD therapy. Joint Bone Spine 74, 73, 2007.

12. Coates, L.C., Cawkwell, L.S., Ng, N.W., Bennett, A.N., Bryer, D.J., Fraser, A.D., Emery, P., and Marzo-Ortega, H. Real life experience confirms sustained response to longterm biologics and switching in ankylosing spondylitis. Rheumatology (Oxf) 47, 897, 2008.

13. Lin, J., Ziring, D., Desai, S., Kim, S., Wong, M., Korin, Y., Braun, J., Reed, E., Gjepitson, D., and Singh, R.R. TNFalpha blockade in human diseases: an overview of efficacy and safety. Clin Immunol 126, 13, 2008.

14. Mittendorf, T., Dietz, B., Sterz, R., Kupper, H., Cifaldi, M.A., and von der Schulenburg, J.M. Improvement and longterm maintenance of quality of life during treatment with adalimumab in severe rheumatoid arthritis. J Rheumatol 34, 2343, 2007.

15. Dhillon, S., Lyseng-Williamson, K.A., and Scott, L.J. Etanercept: a review of its use in the management of rheumatoid arthritis. Drugs 67, 1211, 2007.

16. Hyrich, K.L., Symmons, D.P., Watson, K.D., and Silman, A.J. Comparison of the response to infliximab or etanercept monotherapy with the response to cotherapy with methotrexate or another disease-modifying antirheumatic drug in patients with rheumatoid arthritis: results from the British Society for Rheumatology Biologics Register. Arthritis Rheum 54, 1786, 2006.

17. Chang, J. Clinical use of anti-TNF- $\alpha$ biological agents. Aust Fam Physician 36, 1035, 2007.

18. Ikeda, K., Cox, S., and Emery, P. Aspects of early arthritis. Biological therapy in early arthritis-overtreatment or the way to go? Arthritis Res Ther 9, 211, 2007.

19. Bertele, V., Assisi, A., Di Muzio, V., Renzo, D., and Garattini, S. New antirheumatic drugs: any real added value? A critical overview of regulatory criteria for their marketing approval. Eur J Clin Pharmacol 63, 879, 2007.

20. Gomez-Reino, J.J., Carmona, L., Valverde, V.R., Mola, E.M., and Montero, M.D. Treatment of rheumatoid arthritis with tumor necrosis factor inhibitors may predispose to significant increase in tuberculosis risk: a multicenter activesurveillance report. Arthritis Rheum 48, 2122, 2003.

21. Bruce, S.P., and Boyce, E.G. Update on abatacept: a selective costimulation modulator for rheumatoid arthritis. Ann Pharmacother 41, 1153, 2007.

22. Wang, D., Miller, S.C., Sima, M., Parker, D., Buswell, H., Goodrich, K.C., Kopeckova, P., and Kopecek, J. The arthrotropism of macromolecules in adjuvant-induced arthritis rat model: a preliminary study. Pharm Res 21, 1741, 2004.

23. Butoescu, N., Jordan, O., and Doelker, E. Intra-articular drug delivery systems for the treatment of rheumatic diseases: a review of the factors influencing their performance. Eur J Pharm Biopharm 73, 205, 2009.

24. Maham, A., Tang, Z., Wu, H., Wang, J., and Lin, Y. Proteinbased nanomedicine platforms for drug delivery. Small 5, 1706, 2009.

25. Lee, K.Y., Peters, M.C., Anderson, K.W., and Mooney, D.J. Controlled growth factor release from synthetic extracellular matrices. Nature 408, 998, 2000.

26. Stoop, R. Smart biomaterials for tissue engineering of cartilage. Injury 39 Suppl 1, S77, 2008.

27. Anitua, E., Sanchez, M., Orive, G., and Andia, I. Delivering growth factors for therapeutics. Trends Pharmacol Sci 29, 37, 2008.

28. Puebla, P., Pastoriza, P., Barcia, E., and FernandezCarballido, A. PEG-derivative effectively modifies the characteristics of indomethacin-PLGA microspheres destined to intra-articular administration. J Microencapsul 22, 793, 2005.

29. Balmayor, E.R., Tuzlakoglu, K., Azevedo, H.S., and Reis, R.L. Preparation and characterization of starch-poly-epsiloncaprolactone microparticles incorporating bioactive agents for drug delivery and tissue engineering applications. Acta Biomater 5, 1035, 2009.

30. Howard, K.A., Paludan, S.R., Behlke, M.A., Besenbacher, F., Deleuran, B., and Kjems, J. Chitosan/siRNA nanoparticlemediated TNF-alpha knockdown in peritoneal macrophages for anti-inflammatory treatment in a murine arthritis model. Mol Ther 17, 162, 2009.

31. Silva, G.A., Coutinho, O.P., Ducheyne, P., Shapiro, I.M., and Reis, R.L. Starch-based microparticles as vehicles for the delivery of active platelet-derived growth factor. Tissue Eng 13, 1259, 2007.

32. Larsen, C., Ostergaard, J., Larsen, S.W., Jensen, H., Jacobsen, S., Lindegaard, C., and Anderson, P.H. Intra-articular depot formulation principles: role in the management of postoperative pain and arthritic disorders. J Pharm Sci 97, $4622,2008$.

33. Gerwin, N., Hops, C., and Lucke, A. Intraarticular drug delivery in osteoarthritis. Adv Drug Deliv Rev 58, 226, 2006.

34. Jain, K.K. Nanomedicine: application of nanobiotechnology in medical practice. Med Princ Pract 17, 89, 2008.

35. Liggins, R.T., Cruz, T., Min, W., Liang, L., Hunter, W.L., and Burt, H.M. Intra-articular treatment of arthritis with microsphere formulations of paclitaxel: biocompatibility and efficacy determinations in rabbits. Inflamm Res 53, 363, 2004.

36. Fiehn, C., Muller-Ladner, U., Gay, S., Krienke, S., Freudenberg-Konrad, S., Funk, J., Ho, A., Sinn, H., and 
Wunder, A. Albumin-coupled methotrexate (MTX-HSA) is a new anti-arthritic drug which acts synergistically to MTX. Rheumatology (Oxf) 43, 1097, 2004.

37. Liang, L.S., Jackson, J., Min, W., Risovic, V., Wasan, K.M., and Burt, H.M. Methotrexate loaded poly(L-lactic acid) microspheres for intra-articular delivery of methotrexate to the joint. J Pharm Sci 93, 943, 2004.

38. Bragdon, B., Bertone, A.L., Hardy, J., Simmons, E.J., and Weisbrode, S.E. Use of an isolated joint model to detect early changes induced by intra-articular injection of paclitaxel-impregnated polymeric microspheres. J Invest Surg 14, 169, 2001.

39. Jung, Y., Chung, Y.I., Kim, S.H., Tae, G., Kim, Y.H., Rhie, J.W., and Kim, S.H. In situ chondrogenic differentiation of human adipose tissue-derived stem cells in a TGF-beta1 loaded fibrin-poly(lactide-caprolactone) nanoparticulate complex. Biomaterials 30, 4657, 2009.

40. Oliveira, J.M., Sousa, R.A., Kotobuki, N., Tadokoro, M., Hirose, M., Mano, J.F., Reis, R.L., and Ohgushi, H. The osteogenic differentiation of rat bone marrow stromal cells cultured with dexamethasone-loaded carboxymethylchitosan/ poly(amidoamine) dendrimer nanoparticles. Biomaterials 30, 804, 2009.

41. Park, J.S., Yang, H.N., Woo, D.G., Chung, H.M., and Park, K.H. In vitro and in vivo chondrogenesis of rabbit bone marrow-derived stromal cells in fibrin matrix mixed with growth factor loaded in nanoparticles. Tissue Eng Part A 15, 2163, 2009.

42. Rothenfluh, D.A., Bermudez, H., O'Neil, C.P., and Hubbell, J.A. Biofunctional polymer nanoparticles for intra-articular targeting and retention in cartilage. Nat Mater 7, 248, 2008.

43. Chandrasekar, D., Sistla, R., Ahmad, F.J., Khar, R.K., and Diwan, P.V. The development of folate-PAMAM dendrimer conjugates for targeted delivery of anti-arthritic drugs and their pharmacokinetics and biodistribution in arthritic rats. Biomaterials 28, 504, 2007.

44. Metselaar, J.M., van den Berg, W.B., Holthuysen, A.E., Wauben, M.H., Storm, G., and van Lent, P.L. Liposomal targeting of glucocorticoids to synovial lining cells strongly increases therapeutic benefit in collagen type II arthritis. Ann Rheum Dis 63, 348, 2004.

45. Horisawa, E., Hirota, T., Kawazoe, S., Yamada, J., Yamamoto, H., Takeuchi, H., and Kawashima, Y. Prolonged anti-inflammatory action of DL-lactide/glycolide copolymer nanospheres containing betamethasone sodium phosphate for an intra-articular delivery system in antigeninduced arthritic rabbit. Pharm Res 19, 403, 2002.

46. Wang, D., Miller, S.C., Liu, X.M., Anderson, B., Wang, X.S., and Goldring, S.R. Novel dexamethasone-HPMA copolymer conjugate and its potential application in treatment of rheumatoid arthritis. Arthritis Res Ther 9, R2, 2007.

47. Nakajima, A. Application of cellular gene therapy for rheumatoid arthritis. Mod Rheumatol Jpn Rheum Assoc 16, 269, 2006.

48. Tarner, I.H., Neumann, E., Gay, S., Fathman, C.G., and Muller-Ladner, U. Developing the concept of adoptive cellular gene therapy of rheumatoid arthritis. Autoimmun Rev 5, 148, 2006.

49. Steinert, A.F., Noth, U., and Tuan, R.S. Concepts in gene therapy for cartilage repair. Injury 39 Suppl 1, S97, 2008.

50. Gelse, K., and Schneider, H. Ex vivo gene therapy approaches to cartilage repair. Adv Drug Deliv Rev 58, 259, 2006.
51. Cucchiarini, M., and Madry, H. Gene therapy for cartilage defects. J Gene Med 7, 1495, 2005.

52. Chen, H.C., Chang, Y.H., Chuang, C.K., Lin, C.Y., Sung, L.Y., Wang, Y.H., and Hu, Y.C. The repair of osteochondral defects using baculovirus-mediated gene transfer with de-differentiated chondrocytes in bioreactor culture. Biomaterials 30, 674, 2009.

53. Vogt, S., Ueblacker, P., Geis, C., Wagner, B., Wexel, G., Tischer, T., Kauger, A., Plank, C., Anton, M., Martinek, V., Imhoff, A.B., and Gansbacher, B. Efficient and stable gene transfer of growth factors into chondrogenic cells and primary articular chondrocytes using a VSV.G pseudotyped retroviral vector. Biomaterials 29, 1242, 2008.

54. Lu, F.Z., Fujino, M., Kitazawa, Y., Uyama, T., Hara, Y., Funeshima, N., Jiang, J.Y., Umezawa, A., and Li, X.K. Characterization and gene transfer in mesenchymal stem cells derived from human umbilical-cord blood. J Lab Clin Med 146, 271, 2005.

55. Byers, S., Rothe, M., Lalic, J., Koldej, R., and Anson, D.S. Lentiviral-mediated correction of MPS VI cells and gene transfer to joint tissues. Mol Genet Metab 97, 102, 2009.

56. Amos, N., Lauder, S., Evans, A., Feldmann, M., and Bondeson, J. Adenoviral gene transfer into osteoarthritis synovial cells using the endogenous inhibitor IkappaBalpha reveals that most, but not all, inflammatory and destructive mediators are NFkappaB dependent. Rheumatology (Oxf) 45, 1201, 2006.

57. Hromadnikova, I., Zlacka, D., Hien Nguyen, T.T., Sedlackova, L., Zejskova, L., and Sosna, A. Fetal cells of mesenchymal origin in cultures derived from synovial tissue and skin of patients with rheumatoid arthritis. Joint Bone Spine 75, 563, 2008.

58. Haag, J., Voigt, R., Soeder, S., and Aigner, T. Efficient nonviral transfection of primary human adult chondrocytes in a high-throughput format. Osteoarthritis Cartilage 17, 813, 2009.

59. Guo, X., Zheng, Q., Yang, S., Shao, Z., Yuan, Q., Pan, Z., Tang, S., Liu, K., and Quan, D. Repair of full-thickness articular cartilage defects by cultured mesenchymal stem cells transfected with the transforming growth factor beta1 gene. Biomed Mater 1, 206, 2006.

60. Palmer, G.D., Steinert, A., Pascher, A., Gouze, E., Gouze, J.N., Betz, O., Jonhstone, B., Evans, G.H., and Ghivizzani, S.C. Gene-induced chondrogenesis of primary mesenchymal stem cells in vitro. Mol Ther 12, 219, 2005.

61. Romero-Prado, M., Blazquez, C., Rodriguez-Navas, C., Munoz, J., Guerrero, I., Delgado-Baeza, E., and GarciaRuiz, J.P. Functional characterization of human mesenchymal stem cells that maintain osteochondral fates. J Cell Biochem 98, 1457, 2006.

62. Tew, S.R., Clegg, P.D., Brew, C.J., Redmond, C.M., and Hardingham, T.E. SOX9 transduction of a human chondrocytic cell line identifies novel genes regulated in primary human chondrocytes and in osteoarthritis. Arthritis Res Ther 9, R107, 2007.

63. Tew, S.R., Pothacharoen, P., Katopodi, T., and Hardingham, T.E. SOX9 transduction increases chondroitin sulfate synthesis in cultured human articular chondrocytes without altering glycosyltransferase and sulfotransferase transcription. Biochem J 414, 231, 2008.

64. Sung, L.Y., Chiu, H.Y., Chen, H.C., Chen, Y.L., Chuang, C.K., and $\mathrm{Hu}$, Y.C. Baculovirus-mediated growth factor expression in dedifferentiated chondrocytes accelerates 
redifferentiation: effects of combinational transduction. Tissue Eng Part A 15, 1353, 2009.

65. Kuroda, R., Usas, A., Kubo, S., Corsi, K., Peng, H., Rose, T., Cummins, J., Fu, F.H., and Huard, J. Cartilage repair using bone morphogenetic protein 4 and muscle-derived stem cells. Arthritis Rheum 54, 433, 2006.

66. Matsumoto, T., Cooper, G.M., Gharaibeh, B., Meszaros, L.B., Li, G., Usas, A., Fu, F.H., and Huard, J. Cartilage repair in a rat model of osteoarthritis through intraarticular transplantation of muscle-derived stem cells expressing bone morphogenetic protein 4 and soluble Flt. Arthritis Rheum 60, 1390, 2009.

67. Pagnotto, M.R., Wang, Z., Karpie, J.C., Ferretti, M., Xiao, X., and Chu, C.R. Adeno-associated viral gene transfer of transforming growth factor-beta1 to human mesenchymal stem cells improves cartilage repair. Gene Ther 14, 804, 2007.

68. Tie, L., Hong-bo, Y., Han-feng, G., An-min, C., and Feng L. Construction of eukaryotic expression plasmid human transforming growth factor beta 3 and its transfection into precartilaginous stem cells. Chin J Traumatol 10, 288, 2007.

69. Nita, I., Ghivizzani, S.C., Galea-Lauri, J., Bandara, G., Georgescu, H.I., Robbins, P.D., and Evans, C.H. Direct gene delivery to synovium. An evaluation of potential vectors in vitro and in vivo. Arthritis Rheum 39, 820, 1996.

70. Guo, T., Zhao, J., Chang, J., Ding, Z., Hong, H., Chen, J., and Zhang, J. Porous chitosan-gelatin scaffold containing plasmid DNA encoding transforming growth factorbeta1 for chondrocytes proliferation. Biomaterials 27, 1095, 2006.

71. Capito, R.M., and Spector, M. Collagen scaffolds for nonviral IGF-1 gene delivery in articular cartilage tissue engineering. Gene Ther 14, 721, 2007.

72. Luu, Y.K., Kim, K., Hsiao, B.S., Chu, B., and Hadjiargyrou, M. Development of a nanostructured DNA delivery scaffold via electrospinning of PLGA and PLA-PEG block copolymers. J Control Release 89, 341, 2003.

73. Sun, X.D., Jeng, L., Bolliet, C., Olsen, B.R., and Spector, M. Non-viral endostatin plasmid transfection of mesenchymal stem cells via collagen scaffolds. Biomaterials 30, 1222, 2009.

74. Evans, C.H., Ghivizzani, S.C., and Robbins, P.D. Gene therapy of the rheumatic diseases: 1998 to 2008. Arthritis Res Ther 11, 209, 2009.

75. Ringe, J., Haupl, T., and Sittinger, M. Future of tissue engineering in rheumatic diseases. Expert Opin Biol Ther 7, 283, 2007.

76. Marques, A.P., Reis, R.L., and Hunt, J.A. Cytokine secretion from mononuclear cells cultured in vitro with starch-based polymers and poly-L-lactide. J Biomed Mater Res A 71, 419, 2004.

77. Silva, G.A., Costa, F.J., Neves, N.M., Coutinho, O.P., Dias, A.C.P., and Reis, R.L. Entrapment ability and release profile of corticosteroids from starch-based microparticles. J Biomed Mater Res Part A 73A, 234, 2005.

78. Silva, G.A., Coutinho, O.P., Ducheyne, P., Shapiro, I.M., and Reis, R.L. Starch-based microparticles as vehicles for the delivery of active platelet-derived growth factor. Tissue Eng 13, 1259, 2007.

79. Silva, G.A., Coutinho, O.P., Ducheyne, P., Shapiro, I.M., and Reis, R.L. The effect of starch and starch-bioactive glass composite microparticles on the adhesion and expression of the osteoblastic phenotype of a bone cell line. Biomaterials 28, 326, 2007.
80. Wang, Q., Zhang, N., Hu, X., Yang, J., and Du, Y. Chitosan/ starch fibers and their properties for drug controlled release. Eur J Pharm Biopharm 66, 398, 2007.

81. Elfstrand, L., Eliasson, A.C., and Wahlgren, M. The effect of starch material, encapsulated protein and production conditions on the protein release from starch microspheres. J Pharm Sci 98, 3802, 2009.

82. Simi, C.K., and Emilia Abraham, T. Hydrophobic grafted and cross-linked starch nanoparticles for drug delivery. Bioprocess Biosyst Eng 30, 173, 2007.

83. Malafaya, P.B., Elvira, C., Gallardo, A., San Roman, J., and Reis, R.L. Porous starch-based drug delivery systems processed by a microwave route. J Biomater Sci Polym Ed 12, 1227, 2001.

84. Balmayor, E.R., Tuzlakoglu, K., Marques, A.P., Azevedo, H.S., and Reis, R.L. A novel enzymatically-mediated drug delivery carrier for bone tissue engineering applications: combining biodegradable starch-based microparticles and differentiation agents. J Mater Sci Mater Med 19, 1617, 2008.

85. Knutsen, G., Drogset, J.O., Engebretsen, L., Grontvedt, T., Isaksen, V., Ludvigsen, T.C., Roberts, S., Solheim, E., Strand, T., and Johansen, O. A randomized trial comparing autologous chondrocyte implantation with microfracture. Findings at five years. J Bone Joint Surg 89, 2105, 2007.

86. Estes, B.T., Wu, A.W., and Guilak, F. Potent induction of chondrocytic differentiation of human adipose-derived adult stem cells by bone morphogenetic protein 6 . Arthritis Rheum 54, 1222, 2006.

87. Ringe, J., and Sittinger, M. Tissue engineering in the rheumatic diseases. Arthritis Res Ther 11, 211, 2009.

88. Vilquin, J.T., and Rosset, P. Mesenchymal stem cells in bone and cartilage repair: current status. Regen Med 1, 589, 2006.

89. Pittenger, M.F., Mackay, A.M., Beck, S.C., Jaiswal, R.K., Douglas, R., Mosca, J.D., Moorman, M.A., Simonetti, D.W., Craig, S., and Marshak, D.R. Multilineage potential of adult human mesenchymal stem cells. Science 284, 143, 1999.

90. Noth, U., Steinert, A.F., and Tuan, R.S. Technology insight: adult mesenchymal stem cells for osteoarthritis therapy. Nat Clin Pract Rheumatol 4, 371, 2008.

91. Jorgensen, C., Djouad, F., Fritz, V., Apparailly, F., Plence, P., and Noel, D. Mesenchymal stem cells and rheumatoid arthritis. Joint Bone Spine 70, 483, 2003.

92. Tuan, R.S. Stemming cartilage degeneration: adult mesenchymal stem cells as a cell source for articular cartilage tissue engineering. Arthritis Rheum 54, 3075, 2006.

93. Fan, H., Zhang, C., Li, J., Bi, L., Qin, L., Wu, H., and Hu, Y. Gelatin microspheres containing TGF-beta3 enhance the chondrogenesis of mesenchymal stem cells in modified pellet culture. Biomacromolecules 9, 927, 2008.

94. Alves da Silva, M.L., Crawford, A., Mundy, J.M., Martins, A., Araujo, J.V., Hatton, P.V., Reis, R.L., and Neves, N.M. Evaluation of extracellular matrix formation in PCL and SPCL nanofiber meshes when seeded with bovine articular chondrocytes. Tissue Eng 15, 377, 2009.

95. Mrugala, D., Bony, C., Neves, N., Caillot, L., Fabre, S., Moukoko, D., Jorgensen, C., and Noel, D. Phenotypic and functional characterisation of ovine mesenchymal stem cells: application to a cartilage defect model. Ann Rheum Dis 67, 288, 2008.

96. Park, H., Temenoff, J.S., Tabata, Y., Caplan, A.I., and Mikos, A.G. Injectable biodegradable hydrogel composites for rabbit marrow mesenchymal stem cell and growth factor delivery for cartilage tissue engineering. Biomaterials 28, 3217, 2007. 
97. Hui, J.H., Chan, S.W., Li, J., Goh, J.C., Li, L., Ren, X.F., et al. Intra-articular delivery of chondroitin sulfate for the treatment of joint defects in rabbit model. J Mol Histol 38, 483, 2007.

98. Tan, H., Chu, C.R., Payne, K.A., and Marra, K.G. Injectable in situ forming biodegradable chitosan-hyaluronic acid based hydrogels for cartilage tissue engineering. Biomaterials 30, 2499, 2009.

99. Pereira, C.S., Cunha, A.M., Reis, R.L., Vazquez, B., and San Roman, J. New starch-based thermoplastic hydrogels for use as bone cements or drug-delivery carriers. J Mater Sci Mater Med 9, 825, 1998.

100. Oliveira, J.T., Picciochi, R., Santos, T.C., Martins, L., Pinto, L.G., Malafaya, P.B., Sousa, R.A., Marques, A.P., Castro, A.G., Mano, J.F., Neves, N.M., and Reis, R.L. Injectable gellan gum hydrogels as supports for cartilage tissue engineering applications. Tissue Eng 14, 748, 2008.

101. Lima, H.C., Araujo, J.V., Neves, N., Mano, J.F., and Reis, R.L. Cell encapsulation in thermoresponsive chitosan based hydrogels for cartilage tissue engineering. Tissue Eng 14, 709, 2008.

102. Pereira, R.C., Scaranari, M., Castagnola, P., Grandizio, M., Azevedo, H.S., Reis, R.L., Cancedda, R., and Gentili, C.
Novel injectable gel (system) as a vehicle for human articular chondrocytes in cartilage tissue regeneration. J Tissue Eng Regen Med 3, 97, 2009.

103. Sittinger, M., and Burmester, G.R. Can engineered cartilage transplants be used for treating rheumatic diseases? Nat Clin Pract 2, 172, 2006.

Address correspondence to: Marta Alves da Silva, M.Sc. 3B's Research Group-Biomaterials, Biodegradables, and Biomimetics Department of Polymer Engineering University of Minho Avepark, Zona Industrial da Gandra S. Claúdio do Barco 4806-909 Caldas das Taipas, Guimarães Portugal

E-mail: msilva@dep.uminho.pt

Received: August 3, 2009

Accepted: December 21, 2009

Online Publication Date: January 27, 2010 
